\title{
Possible immunological consequences of filaggrin gene mutation. A case study of a 3-year-old allergic girl
}

\author{
ANNA OGRODOWCZYK, BARBARA WRÓBLEWSKA, LIDIA HANNA MARKIEWICZ, \\ MAGDALENA ZAKRZEWSKA
}

Institute of Animal Reproduction and Food Research of Polish Academy of Sciences, Poland Non-Public Health Care Clinic of Allergy "ALLERGICA", Olsztyn, Poland

\begin{abstract}
Filaggrin is one of the most important structural proteins in the stratum corneum of the human's epidermis. There are known over forty mutations in the filaggrin gene (FLG) of which the null-type mutations such as R501X and 2282del4, localized in exon 3 of this gene, are the most significant risk factors for the development of allergic diseases. The atopic diseases develop in mucosal surfaces such as the gastrointestinal tract, the respiratory tract and the skin. We focus on research characterizing the filaggrin-deficient epidermis with respect to genetic, immunologic and microbiome abnormalities to show the consequences of these mutations in the development and progression of atopy. A case of a 3-yearold girl with food allergy, atopic dermatitis and Staphylococcus aureus infection, which was found by the presence of $R 501 X$ mutation in the filaggrin gene. The girl remains under strict medical control and is subjected to integrated therapy of allergic diseases.
\end{abstract}

Key words: Filaggrin mutation, food allergy, atopic dermatitis, Staphylococcus aureus infection.

(Centr Eur J Immunol 2013; 38 (3): 403-407)

\section{Introduction}

This paper describes a case of a 3-year-old girl with atopic dermatitis, sensitized to milk, eggs, pork meat, celery and grain flour proteins. The girl was born by caesarean section. She had neither history of allergy nor eczema in the family. During the first four weeks of life, she was exclusively breast-fed with no supplementation. In the second month of life, she experienced symptoms of atopic dermatitis that were worsened by products containing cow's milk, eggs and celery in the mother's diet. The level of total IgE in serum was determined at $468.5 \mathrm{kU} / \mathrm{l}$. Although the child's symptoms always correlated with specific food, it was difficult for the mother to follow the elimination diet successfully due to the presence of hidden allergens. In the third month of the girl's life, she often started to vomit a few minutes after feeding and suffered from alternating constipation and diarrhea. She had also a similar reaction to Nutramigen (an extensively hydrolyzed casein) and Bebilon Pepti (an extensive- ly hydrolyzed whey protein) enhanced with shortness of breath. She required many hospitalizations for dehydration and low body mass (weight at the $13^{\text {th }}$ percentile and height at the $25^{\text {th }}$ percentile). According to the SCORAD scale, $97 \%$ of her skin had been affected by the severe ( 3 according to 0-3 scale of intensity) signs along with oozing, abscesses and crusting, by the end of her first year of life. Laboratory data revealed infection of scarves by methicillin-resistant Staphylococcus aureus. After further analysis, the presence of this strain in feces, urine and saliva samples was confirmed. Beside this, in the swab from the throat and sinuses, penicillin-resistant Streptococcus viridans was also present. During hospitalization, a diet with an amino acid-based formula Bebilon Amino (Nutricia) and Neocate (SHS) was successfully introduced. Since then, she was on this type of diet until the age of two. During the $17^{\text {th }}$ month of life there were attempts to gradually turn to the diet of bread and biscuits but symptoms such as abdominal pain and vomiting occurred. After this diet she was at the $35^{\text {th }}$ percentile for 
weight. It is worth mentioning that the pork meat, hen's egg, celery were not included in the child's diet and her symptoms also did not always correlate with specific food. Finally, she was instructed to avoid milk, dairy products, bread and products based on wheat and corn flour, celery and chicken eggs. She was also treated with Cetirizine and Hydroxyzine and underwent a full Cefotaxime therapy. The mother of the girl currently prepares all the meals on her own and the child does not eat any readymade products. During the last year, the total serum IgE level did not decrease in spite of proposed treatment. The slow atopic dermatitis (AD) wound healing has led to looking for possible null-type mutations in the filaggrin gene (FLG) in the described patient. The increasing number of products that trigger response from the gastrointestinal tract increased interest in the patient's gut condition.

\section{Material and methods}

Blood and stool samples were obtained from a 3-yearold girl suffering from food allergy and atopic dermatitis with a previously diagnosed infection of $S$. aureus. The procedures were followed in accordance to the Helsinki Declaration of 1975, revised in 2000, and with the standards of the local ethical committee that gave the approval for conducting the research (Case No. 2/2010).

\section{Immunological analysis}

The patient's total IgE level was measured using ImmunoCAP (Phadia AB, Uppsala, Sweden), and food specific serum IgE has been determined with EUROLINE Pediatric profile for allergy diagnosis (EUROIMMUN AG, Lübeck, Germany). Tests were confirmed by the percutaneous skin tests (Allergopharma-Nexter, Germany). The patient's serum IgG and cytokine (e.g. IL-2, IL-4, INF- $\gamma$ ) levels have been determined by means of the enzyme linked immunosorbent assay method (ELISA) (BD Bioscience, USA). The levels of patient's secretory IgA, Calprotectin and $\alpha$-1-antitripsine (A1AT) were evaluated in the stool sample also with the enzyme linked immunosorbent assay method (ELISA) (ImmunDiagnostik AG, Germany).

\section{Molecular analysis}

Genomic DNA was isolated from EDTA blood samples according to the protocols of the producer (EURx Molecular Biology Products, Gdańsk, Poland).
The analysis of the R501X (c.1501C>T) mutation of the FLG gene required genomic DNA amplification according to the Smith et al. 2006 protocol. The protocol: PCR mixture buffer containing $1.5 \mathrm{mM} \mathrm{MgCl}$, Taq polymerase, primer pair FilH1F3/RPT1P6 using the Eppendorf MasterCycler ${ }^{\circledR}$ gradient (Eppendorf, Germany). PCR conditions were as follows: $94^{\circ} \mathrm{C}$ for $5 \mathrm{~min} ; 30 \times$ of $94^{\circ} \mathrm{C} / 30 \mathrm{~s}, 58^{\circ} \mathrm{C} / 45 \mathrm{~s}$, $72^{\circ} \mathrm{C} / 1 \mathrm{~min}$; at the end one cycle $72^{\circ} \mathrm{C}$ for $5 \mathrm{~min}$. The presence of p.R501X mutation creates a specific Hin1II (NlaIII - Fermentas) restriction site. Products were digested: 5 Unit, $4 \mathrm{~h}$ at $37^{\circ} \mathrm{C}$ and resolved in $3 \%$ high resolution agarose gel.

The analysis of the c.2282del4 mutation also required amplification with the primer pair RPT1P7/RPT2P1 and enzyme digestion. PCR conditions were as follows: $94^{\circ} \mathrm{C}$ for $5 \mathrm{~min} ; 35 \times$ of $94^{\circ} \mathrm{C} / 30 \mathrm{~s}, 57^{\circ} \mathrm{C} / 45 \mathrm{~s}, 72^{\circ} \mathrm{C} / 1 \mathrm{~min} 30 \mathrm{~s}$; at the end, one cycle $72^{\circ} \mathrm{C}$ for $5 \mathrm{~min}$. The presence of $2282 \mathrm{del} 4$ mutation creates a specific AdeI (DraIII - Fermentas) restriction site. Products were digested: 5 Unit, $4 \mathrm{~h}$ at $37^{\circ} \mathrm{C}$, and resolved in $2 \%$ high resolution agarose gel. Amplified PCR products were also resolved in $1.5 \%$ agarose gel, purified according to the protocols of the producer (EURx Molecular Biology Products, Gdańsk, Poland) and sequenced using Genome Sequencer Junior.

\section{Results \\ Immunological analysis}

The patient's total IgE and IgG serum level significantly exceeded the standard norm required for the age (Table 1). The specific serum IgE test results were markedly positive for both egg white and yolk, milk, wheat, walnut, soybean and raw potato (Table 2). The percutaneous skin test results confirmed multiple hypersensitivity (Table 3). The test result was considered positive if the wheal diameter was $3 \mathrm{~mm}$ or more greater than the negative control.

The levels of pro-inflammatory cytokines such as IFN- $\gamma$, IL-2 were detectable and IL-4 in the serum sample were undetectable. The profile of cytokines produced by peripheral blood cells indicate Th1 type of response. Otherwise, the increased level of $\mathrm{IgE}$ and $\mathrm{IgG}$ in serum can partially explain the lack of IL-4 and it indicates the active IgE-mediated mechanism of allergy. The level of secretory $\operatorname{IgA}$ in a stool sample was also high. However, it was in the normal range in contrast to calprotectin, the level of which was significantly higher than the normal range $(178.2 \mu \mathrm{g} / \mathrm{g})$. Cal-

Table 1. Results of serum and stool samples and the norm appropriate for the age

\begin{tabular}{|c|c|c|c|c|c|}
\hline Type of test & Result & Normal range [test limit sensitivity] & Type of test & Result & Normal range \\
\hline INF- $\gamma$ & $128.12 \pm 4.14 \mathrm{pg} / \mathrm{ml}$ & {$[4.7-300 \mathrm{pg} / \mathrm{ml}]$} & $\operatorname{IgE}$ & $1107 \mathrm{kU} / \mathrm{L}$ & $<40 \mathrm{kU} / \mathrm{L}$ \\
\hline IL-2 & $22.72 \pm 1.82 \mathrm{pg} / \mathrm{ml}$ & {$[7.8-500 \mathrm{pg} / \mathrm{ml}]$} & $\operatorname{sIg} \mathrm{A}$ & $1714 \pm 7.89 \mu \mathrm{g} / \mathrm{g}$ & $510-2040 \mu \mathrm{g} / \mathrm{g}$ \\
\hline IL-4 & below & {$[7.8-500 \mathrm{pg} / \mathrm{ml}]$} & calprotectin & $178.2 \pm 1.18 \mu \mathrm{g} / \mathrm{g}$ & $<166 \mu \mathrm{g} / \mathrm{g}$ \\
\hline $\mathrm{IgG}$ & $23.3 \pm 1.13 \mathrm{~g} / 1$ & $9.0-15.0 \mathrm{~g} / 1$ & A1AT & $15.98 \pm 2.21 \mathrm{mg} / \mathrm{dl}$ & $<26.8 \mathrm{mg} / \mathrm{dl}$ \\
\hline
\end{tabular}


Table 2. Food-specific serum IgE results. The normal range for all $<0.35(\mathrm{kU} / \mathrm{L})$

\begin{tabular}{lcc}
\hline Type of allergens & Patient range (kU/L) & Class of reaction \\
\hline egg white (f1) & 42 & 4 \\
\hline egg yolk (f75) & 13.5 & 3 \\
\hline milk (f2) & 9.59 & 3 \\
\hline$\alpha$-lactoalbumin (f76) & 2.5 & 2 \\
\hline$\beta$-lactoglobulin (f77) & $<0.35$ & 0 \\
\hline casein (f78) & 1.1 & 2 \\
\hline soybean (f14) & 10.6 & 3 \\
\hline codfish (f3) & 0.37 & 1 \\
\hline peanut (f13) & $<0.35$ & 0 \\
\hline walnut (f17) & 10.6 & 3 \\
\hline wheat (f4) & 1.1 & 2 \\
\hline carrot (f31) & $<0.35$ & 0 \\
\hline rice (f9) & $<0.35$ & 0 \\
\hline apple (f49) & $<0.35$ & 0 \\
\hline potato (f35) & 60 & 5 \\
\hline
\end{tabular}

protectin is named after its ability to bind calcium and zinc. It is $36.5 \mathrm{kDa}$ protein expressed by the gene S100. It has bacteriostatic and mycostatic properties, is abundant in neutrophil granulocytes and plays an antimicrobial role in the defense of the organism. An increased calprotectin concentration in stool may be the consequence of neutrophil degranulation due to mucosal damage, which is why it is treated as a marker in many inflammatory bowel diseases $[1,2]$. Also, the level of $\alpha_{1}$-antitrypsin (A1AT) in the stool sample was determined. A1AT is a protease inhibitor, belonging to the serpin family, weight $52 \mathrm{kDa}$. A1AT plays a regulatory and anti-inflammatory role. Fecal A1AT is considered as a marker for the intestinal protein loss and permeability. Moreover, it can be used as a marker of inflammatory intestinal diseases [3]. The result of the test for concentration was estimated as negative, but it is worth mentioning that the result should be expanded to include an assessment of A1AT clearance-measurements.

\section{Molecular analysis}

The molecular analysis revealed the presence of R501X mutation in repeat one of exon three of FLG. The patient has been confirmed to have R501X mutation in the homozygous system. The transition in position $501 \mathrm{C} \rightarrow \mathrm{T}$ resulted in occurrence of null type mutation. The presence of R501X mutation was confirmed in restriction digestion with the Nla III enzyme, as well as during the sequence analysis. 2282del4 has not been detected by any of the used methods (Fig. 1).
Table 3. Percutaneous skin test-result

\begin{tabular}{|c|c|c|}
\hline Type of allergen & Wheal (mm) & Flare (mm) \\
\hline histamine control & 10 & 7 \\
\hline saline control & 1 & 1 \\
\hline pork meat & 5 & 4 \\
\hline chicken meat & 3 & 4 \\
\hline turkey meat & 3 & 3 \\
\hline peanut & - & - \\
\hline walnut & 5 & 4 \\
\hline mandarin & - & - \\
\hline lemon & - & - \\
\hline orange & - & - \\
\hline apple & - & - \\
\hline strawberry & 2 & 3 \\
\hline egg white & 6 & 4 \\
\hline egg yolk & 4 & 4 \\
\hline rye flour & 3 & 2 \\
\hline wheat flour & 6 & 5 \\
\hline corn flour & 5 & 5 \\
\hline cocoa & 3 & 3 \\
\hline tomato & - & - \\
\hline potato & 5 & 5 \\
\hline celery & 7 & 4 \\
\hline pepper & - & - \\
\hline codfish & 2 & 2 \\
\hline milk & 5 & 4 \\
\hline
\end{tabular}

\section{Discussion}

Over the last few years, there has been a significant increase in prevalence of allergic diseases as well as the increased development of knowledge in the field of immunology and allergology. The treatment of patients in many cases can be hampered by a number of possible complications, such as infections but also by genetic mutations. This case was an example of a combined microbiological, immunological and genetic dysfunction. Invalid filaggrin protein in the skin barrier, plays a major role in sensitization to antigens via skin $[4,5]$. Mutations in the filaggrin gene show associations with AD and can exacerbate allergic diseases [6-8]. Moreover, patients with AD may display a significant decrease in the expression of antimicrobial peptides which explains the susceptibility to secondary skin infections with pathogens [9]. It is a result of presence of the null-type filaggrin mutation and reduction in the level 

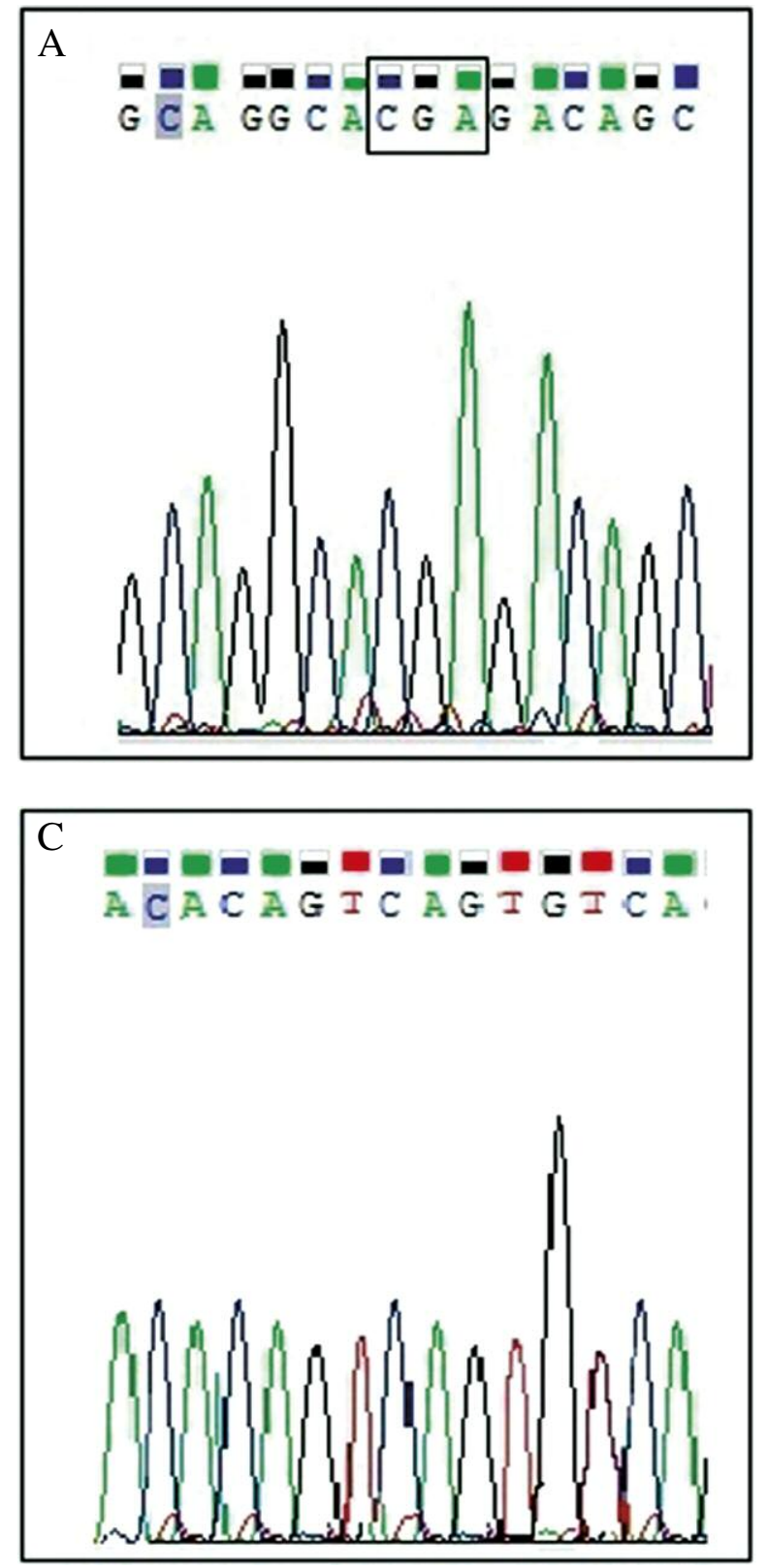

B

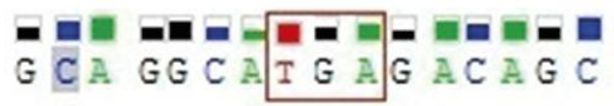

D

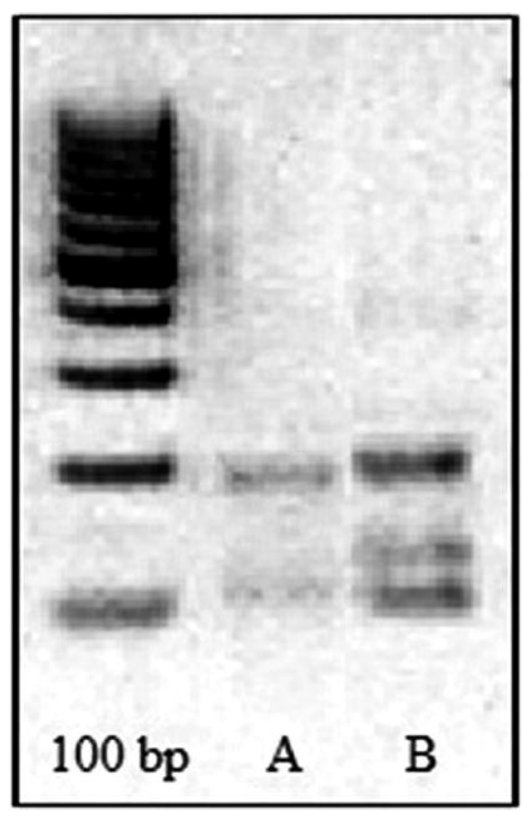

Fig. 1. Filaggrin R501X mutation detection and confirmation A) and B); the lack of 2282del 4 mutation in codon 713-717 C); R501X detection - electrophoresis D)

of filaggrin breakdown products on the skin (urocanic acid - UCA, and pyrrolidone carboxylic acid - PCA). It makes the skin more sensitive to $S$. aureus infection because of its alkalization [10, 11]. The literature data proved that more than $90 \%$ of patients with AD suffer from infection with $S$. aureus $[12,13]$. In many cases, including the one described above, there is a problem with successful therapy because of the strain's resistance to various antibiotics [14]. S. aureus produces enterotoxins that stimulate polyclonal $\mathrm{T}$ cells without requiring antigen presentation. Such activity is known as the superantigen effect [15]. The production of IgE and IgG can be also stimulated by $S$. aureus protein known as fibronectin-binding proteins (FBPs). The protein is important for this strain because of the mechanism of adhesion and invasion dependent on the process of binding FBPs to fibronectin [16]. The mechanism that takes part in developing humoral and cellular immune responses is dependent on antigen presentation [17]. The stimulation with FBP results in a high release of proinflammatory cytokines (e.g. IFN- $\gamma$, IL-6, TNF- $\alpha$ ) which may play an important role in 
various inflammatory processes, including AD. The skin affected by $\mathrm{AD}$ is frequently colonized by $\alpha$-toxinproducing strains of $S$. aureus [18]. It has been discovered that properly formed filaggrin protects keratinocytes against the lethal effects of $\alpha$-toxin and plays a crucial role in protecting cells, by mediating the secretion of sphingomyelinase that reduces the number of $\alpha$-toxin binding sites on the keratinocyte surface. The presence of null-mutation in filaggrin gene results the increased propensity to $S$. aureus infection [19]. Although there is no expression of filaggrin gene in the intestinal epithelium or distal, mid- or proximal esophageal epithelium but the presence of mutation in the genome succeed an increased immunological systemic response [20]. Systemic reaction can increase permeability of intestinal epithelium and can intensify penetration of antigens through the intestinal mucosa that can be an effect of the inflammation state of intestine epithelium. This in turn can lead to abdominal pain, vomiting, nausea and chronic diarrhea [21].

The described case of a 3-year-old girl indicates the need of a multifaceted diagnosis and comprehensive treatment of patients with allergic diseases. Proper diagnosis and early introduced therapy can help avoid complications. The proper care of atopic skin is crucial and no infection should be underestimated. Genetic evaluation of filaggrin mutation can serve as a prognostic tool for diagnosis of atopic diseases. The girl remains under strict medical control and is subjected to integrated therapy of allergic diseases.

The authors declare no conflict of interests.

The authors thank the patient and the family who participated in tests.

The results included in this publication were presented at the conference "Current problems in medical biology" Kazimierz Dolny 16-19.05.2013.

Supported by the European Union within the European social fund and grant no. NN312 311939

\section{References}

1. Costa $F$ (2005): Calprotectin is a stronger predictive marker of relapse in ulcerative colitis than in Crohn's disease. Gut 54: 364-368.

2. Schröder O, Naumann M, Shastri Y, Povse N, Stein J (2007): Prospective evaluation of faecal neutrophil-derived proteins in identifying intestinal inflammation: combination of parameters does not improve diagnostic accuracy of calprotectin. Aliment Pharmacol Ther 26: 1035-1042.

3. Palma-Carlos AG, Amélia Spínola Santos M, Palma-Carlos ML (2008): $S$ and $Z$ variants of alpha-1-antitrypsin and allergic diseases. Int Rev Allergol Clin Immunol 14: 3-4.

4. Hsieh KY, Tsai CC, Wu CH, Lin RH (2003): Epicutaneous exposure to protein antigen and food allergy. Clin Exp Allergy 33: 1067-1075.
5. Palmer CN, Irvine AD, Terron-Kwiatkowski A, et al. (2006): Common loss-of-function variants of the epidermal barrier protein filaggrin are a major predisposing factor for atopic dermatitis. Nat Genet 38: 441-446.

6. Brown SJ, Relton CL, Liao H, et al. (2008): Filaggrin null mutations and childhood atopic eczema: A population-based case-control study. J Allergy Clin Immunol 121: 940,46,e3,

7. van den Oord RA and Sheikh A (2009): Filaggrin gene defects and risk of developing allergic sensitisation and allergic disorders: Systematic review and meta-analysis. BMJ 339: 2433,

8. Polańska A, Dańczak-Pazdrowska A, Silny W, et al. (2012): Evaluation of selected skin barrier functions in atopic dermatitis in relation to the disease severity and pruritus. Postep Derm Alergol 29: 373-377.

9. Lubbe J (2003): Secondary infections in patients with atopic dermatitis. Am J Clin Dermatol 4: 641-654.

10. Miajlovic H, Fallon PG, Irvine AD, Foster TJ (2010): Effect of filaggrin breakdown products on growth of and protein expression by S. aureus. J Allergy Clin Immunol 126: 1184-1190.

11. Kezic S, O' GM, Yau N, et al. (2011): Levels of filaggrin degradation products are influenced by both filaggrin genotype and atopic dermatitis severity. Allergy 66: 934-940.

12. Cai SC, Chen H, Koh WP, et al. (2011): Filaggrin mutations are associated with recurrent skin infection in Singaporean Chinese patients with atopic dermatitis. Br J Dermatol 166: 200-203.

13. Pastuszka M, Matych M, Kaszuba A, et al. (2012): Microorganisms in the etiopathogenesis of atopic dermatitis. Postep Derm Alergol 2012; 29: 215-221.

14. Schlievert PM, Strandberg KL, Lin YC, et al. (2010): Secreted virulence factor comparison between methicillin-resistant and methicillin-sensitive Staphylococcus aureus, and its relevance to atopic dermatitis. J Allergy Clin Immunol 125: 39-49.

15. Fraser JD, Proft T (2008): The bacterial superantigen and superantigen-like proteins. Immunol Rev 225: 226-243.

16. Peacock SJ, Foster TJ, Cameron BJ, Berendt AR (1999): Bacterial fibronectin-binding proteins and endothelial cell surface fibronectin mediate adherence of Staphylococcus aureus to resting human endothelial cells. Microbiology 145: 3477-3486.

17. Reginald K, Westritschnig K, Linhart B, et al. (2011): Staphylococcus aureus fibronectin-binding protein specifically binds $\operatorname{IgE}$ from patients with atopic dermatitis and requires antigen presentation for cellular immune responses. J Allergy Clin Immunol 128: 82-91.

18. Wichmann K, Uter W, Weiss J, et al. (2009): Isolationof alphatoxin-producing Staphylococcus aureus from the skin of highly sensitized adult patients with severe atopic dermatitis. $\mathrm{Br}$ J Dermatol 161: 300-305.

19. Brauweiler AM, Bin L, Kim BE, et al. (2013) Filaggrin-dependent secretion of sphingomyelinase protects against staphylococcal $\alpha$-toxin-induced keratinocyte death. J Allergy Clin Immunol 131: 421-427.

20. De Benedetto A, Qualia CM, Baroody FM, Beck LA (2008): Filaggrin expression in oral, nasal, and esophageal mucosa. J Invest Dermatol 128: 1594-1597.

21. Jyonouchi S, Brown-Whitehorn TA, Spergel JM (2009): Association of eosinophilic gastrointestinal disorders with other atopic disorders. Immunol Allergy Clin North Am 29: 85-97. 